\title{
Physical activity level in Physical Therapy students
}

J Martins ${ }^{1}$, A Costa ${ }^{1}$, A Batista ${ }^{1}$, G Brochado ${ }^{1}$, D Simões $^{2}, S$ Lopes $^{1,3}$ ${ }^{1}$ Escola Superior de Saúde do Vale do Sousa, Portugal

¿Escola Superior de Saúde Santa Maria, Portugal

${ }^{3}$ Centro de Investigação e Reabilitação, Escola Superior de Saúde, Politécnico do Porto, Portugal

Introduction:

Physical activity is defined as any body movement that requests energy expenditure. The practice of physical activity allows to reinforce and increase the capacity of muscular-skeletal response and an improvement of physical aptitude. Currently, has been verified that university students have been decreasing healthy lifestyles and increasing their degree of sedentary lifestyle. Thus, it's essential the Higher Education Institutions present themselves as a way to promote the practice of physical activity and contemplating it in the basic formation.

\section{Objectives:}

Characterize the level of physical activity of students in different years of the physiotherapy course in Escola Superior de Saúde do Vale do Sousa.

\section{Methods:}

Cross-sectional analytical study, with a sample of 179 students.

It was applied a characterization quiz and the International Physical Activity Questionnaire (IPAQ). The data collection was performed in a single moment and it's treatment was performed with the help of SPSS software, whose significance level is 0.05 .

Results:

In the sample, there was an association between the energy spent (MET) and the year of the course $(\mathrm{p}=0.008)$. It was also observed that it's the students of the 1st and 3rd year who have a very high level of physical activity, since they spend weekly 
3342 and 4026 MET's, respectively. Furthermore, it was confirmed the presence of differences in METs from the 1st to the 2 nd year $(p=0.007)$ and from the 2 nd to the 3 rd year $(\mathrm{p}=0.002)$.

Conclusions:

The study showed that students in the 1st and 3rd year are very active and the level of physical activity decreases from $1^{\circ}$ to 2nd and from 3rd to 4 th year. 